\title{
AS EDIÇÕES ELETRÔNIC AS DA REF (E A DEMOCRATIZAÇÃO DO ACESSO À PRODUÇÃO ACADÊMICAE CIENTÍFICA)
}

\author{
SÔNIA WEIDNER MALUF \\ Universidade Federal de Santa Catarina
}

\begin{abstract}
Resumo: Este artigo traz uma breve descrição das public ações eletrônicas da Revista Estudos Feministas e da inserção da REF em uma política de democratização do acesso à produção c ientífic a e acadêmica. Após uma breve descrição das três frentes de publicação eletrônica da Revista (na biblioteca eletrônica SciELO, no portal SciELO Social Science (SSS) e no Portal Feminista ), são pontua das a lguma s questões referentes à contribuição do campo de estudos feministas e de gênero para uma democratização do acesso à produção científica e acadêmica.
\end{abstract}

Palavras-chave: estudos feministas e de gênero; publicações feministas; publicações eletrônicas; democratização da produção científica.

Este artig o traz uma breve desc rição das public ações eletrônicas sa REF e a inserção da Revista em uma política de democratização do acesso à produção científica e acadêmica. São basicamente três as publicações eletrônic as da REF, descritas na seqüência.

1) A edição da REF na scielo.br. A Sc ieELO é um portal de periódicosacadêmicose c ientífic os de acesso aberto e gratuito. Ou, conforme está definido na abertura do site, é uma "biblioteca eletrônica que abrange uma coleção selecionada de periódicoscientífic os brasileiros". Entra ndo no portal, o usuário tem acesso à lista dos periódicos, a o sumário de ca da um e a os a rtig os integ ra is em versã o PDF ou HTML. A REF tem sua versã o eletrônic a na Sc iELO desde 2001, perfa zendo a tua Imente um total, a té o final de 2007, de 17 números. É importante lembrarque a REF faz parte das oito primeiras revistas das área de humanas a ingressarna SciELO, a o la do de outra s como a Episteme (de Filosofia), a Lua Nova, a Revista de Sociologia e Política e o periódico São Paulo em Perspectiva, entre outras. O comitê

Copyright 2008 by Revista Estudos Feministas. 
editorial da SciELO usa um conjunto de critérios cruzados para aprovar o ingresso de periódicos no portal, utilizando diferentes indexadores e as avaliações da Fapesp, do CNPq, a lém da a valia ção porpares - formando em seu conjunto um corpus de a valia ção da qualidade científica dos periódicos. Mas cabe colocarque a própria SciELO acabou virando uma espécie de indexador, na medida em que estarou não no portal influencia a pontua ção dos periód ic os junto a os próp rios comitês a va lia dores. Além disso, a o longo do tempo a SCIELO foi construindo critérios próprios, como a assiduidade ou a tendência a dota da em 2004 de darpreferência ou de estimula ros periódic os a public a rem mais de duas edições anuais. Nesse momento, a partir de uma a valiação sobre as implicações dessa demanda para a área de humanas, que teria uma temporalidade diferente das dema isá reas em rela ção ao desenvolvimento daspesquisa se da produção de resulta dos e public ações, o comitê local da REF inic ia Imente reivind ic ou, junto com outros periódicos das humanas, que esse critério fosse revisto. No entanto, a pós uma avaliação do próprio aumento do fluxo de artigos propostos para public ação, decidiu aumentar o número de ed ições a nua is. Assim, desde 2005 ed itamos três números a nua is da REF, o que, ca be dizer signific ou um a umento signific a tivo do custo, do trabalho e do tempo despendido em sua confecção.

Um dado importante é que não necessariamente o periódico a ser integrado à SciELO é impresso. Existe a possibilidade de periódicos eletrônicos também serem selecionados, no entanto, a SciELO não realiza uma edição própria. Ela, como uma biblioteca eletrônica, apenas disponibiliza on-line os periódicos e os artigos tal e qual foram publicados.

Em 2004 uma segunda revista feminista foi incluída na SciELO, os Cadernos Pagu, que têm publicados onze números a partir do número 19 de 2002. Os Cadernos Pagu editam dois númerosporano.

2) A segunda ed ição eletrônic a da REF é na SciELO Social Sc ience, um portal liga do à SciELO, mas que, buscando implementar uma política de tradução e visibilidade internacional da produção científica e acadêmica brasileira, disponibiliza os artigos em inglês. Uma das especificidades da SSS é que cada periódico tem direito a um volume por a no, com número de páginas proporcional a o número de artigos publicados por a no em cada periódic 0. O u seja, existe uma seleção prévia dosartigos que serã o tra duzidos para o inglês e publicados no portal, sendo inclusos numa mesma edição a rtigos de diferentes números.

Entre nossos critérios de seleção de artigos para a tradução, a lém do critério de qualidade (já contemplado pelo fa to de que praticamente todos os artigos, com exc eção do dossiê, da seção Deba tes e das resenhas, passam porpa rec erista sad hoc especialistas no tema do artigo), adotamos os seguintes critérios, buscando contemplar a proposta e o espírito geral do projeto da SciELO Social Science: temática nacional, reflexão teórica orig inal e consistente; contribuição a o deba te no campo dos estudos feministase de gênero; a utora ou a utorque traba lhe no Brasil; e representatividade porárease representa tivida de regional (esses critérios são orienta ções gera is e nã o regra sestrita s, po is à s vezes o mesmo tema pode ter abordagens tão diferentes e origina is que vários artigos de uma mesma seção temática podem ser escolhidos. Foi o caso da seção Gênero e Juventude, que acabou fomec endo três a rtigos para a SciELO Social Science).

A REF foi um dos primeiros periódicos selecionados para publicação na SSS. Já public a mosduas edições, num total de 13 artigos, e esta moscom uma terceira ed ição em vias de public ação. A Sc iELO Social Sc ience é especia liza da em revistas da área e publica a tua Imente 29 periódicos naciona is e sul-americanos, sendo que desses a REF é a única do campo dos estudos de gênero. Nos dois primeiros volumes, foi o próprio projeto da SSS 
que bancou o custo da publicação, so bretudo em sua parte maiscara, que são as tra duções para o inglês. Com o esgotamento da verba inicial, a última reunião do comitê decidiu compartilhar os custos de tradução com os periódic os e com os autores - $1 / 3$ seria pago pela SSS, 1/3 pelo periódico e 1/3 pelo autor. Apesar de seruma solução pragmática que viabiliza a continuidade do portal, a decisão por incluir os autores no pagamento da public ação merece, no meu modo de ver, uma discussão mais a profundada, na medida em que estende às revistas de Ciências Humanas uma prática que alguns periódicos intemacionais, sobretudo de outras áreas, sustentam, que é o de cobrar para publicar. Minha posição pessoal é a de que a impossibilidade de algum autorarcarcom esse custo de tradução não seja impeditivo para a sua publicação. A importância de se traduzir a produç ão nacional para o ing lês, a língua franca da produção científic a contemporânea, e divulgá-la amplamente é inegável.

3) O terceiro espaço de publicação eletrônica da REF é o Portal Feminista. Esse projeto foi inicialmente financiado pela Fundação Ford e pela UFSC (através de espaço físic 0 , de rec ursos humanos etc.) e hoje busc a formas não apenas de se mantercomo de se a mpliar. O Portal Feminista tem em seu projeto inic ial o objetivo de da racesso e divulgar a produção do campo aca dêmico feminista, incluindo não a penas a edição da REF como outras publicações do campo. Outras demandas foram surgindo, como a de ONGs que manifesta ram, dura nte o Encontro Nacional de Public ações Feminista s, rea liza do em duas edições, o desejo de que suas public ações fossem incorporadas a o Portal.

Atua Imente nós publica mos no Portal Feminista qua tro revista s b rasileira s de estudos de gênero. Além da REF (que está disponível do número 0 a té o último), os Ca dernos Pagu, da Unic amp (do número 1 ao 27), o Caderno Espaço Feminino, public a do pela Universida de Federal de Uberlândia (do volume 9 a o 16), e a revista Gênero, editada pelo Nuteg, na Universida de Federal Fluminense (6 volumes). Além dessas revistas, o portal disponibiliza entrevistas do projeto Memórias do Feminismo.

Uma dasta refas urg entes rela ciona dasa o Portal se refere a o programa e à plata forma utilizada. Pa ra a a mpliação do portal, a inc lusão não a penas de outras public ações, mas de bancos de dadoscom informações de todo o tipo sobre os estudos de gênero no Brasil, o abrigamento de redes de pesquisadoras, a disponibilização de trabalhos, teses e dissertações, a constituição de uma biblioteca virtual de textos e livros sobre gênero e feminismo ${ }^{1}$ etc., é preciso um programa mais ágil e com mais suporte que permita uma interface mais dinâmica e ag radá vel que possa incluir as ca pas das revistas, por exemplo. Claro que um dos problemasé o de custo, e esse é um dos grandes desa fios das publicações eletrônic as brasileiras dos qua is eu vou falar um pouco logo a seguir.

Apesar de todas as dificuldades, o Portal é um dos projetos ma is bem-sucedidos na América Latina de buscarsediara diversidade das public ações aca dêmicase de ensaiar, a tra vés do projeto Memórias do Feminismo, a possibilidade de construção de um imenso banco de dados de livre acesso sobre o feminismo brasileiro e, por que não no futuro, latino-americ ano.

$* * *$

A partir dessa breve descrição dessas três frentes de public açã o eletrônic a da REF, eu gostaria de lançaralguns pontos para uma reflexão sobre o tema.

\footnotetext{
${ }^{1}$ Uma idéia surgida durante o colóquio foi a de digitalizar obras clássic as do feminismo bra sileiro e intemacional, já
} esg otadas, e disponibilizá-las on-line. 
1) 0 primeiro ponto diz respeito a o desa fio de uma polític a de livre acesso à produção acadêmica e científica, quando sabemos que hoje no plano mundial algumas poucas empresa seditoria is detêm grande parte do merca do de publica çõescientífic as, vendendo ca ro o a cesso (vide os ga stos do govemo brasileiro com a manutenção do Portal de Perió dicos da Capes). E diz respeito a inda a que posição o campo aca dêmic o e científic o bra sileiro e particularmente no nosso caso o campo feminista acadêmico irá tomar em relação a essa tendência hegemônica. Nós temos boas notícias, a lém é c la ro do que já foi realiza do com a construção da SciELO e de outros porta is (como o feminista), que é, no pla no mundial, o crescimento do movimento pelo livre acesso e, no caso brasileiro, a formação de uma 'força-tarefa' em prol do livre acesso à literatura científica. Já houve uma reunião em outubro de 2008, em Bra sília, como proposta do Instituto Bra sileiro de Info ma ção em Ciência e Tecnologia (IBICT) para discutira disseminação da produção técnico-científic a bra sileira, a partir da construção de repositórios dig ita is da produção docente e disc ente. O IBICTestá formando, por exemplo, a Biblioteca Digital Bra sileira, que hoje tem ma is de 55 mil teses e dissertações em texto integral; um processo que vai na contra tendência do lobby mundial das grandes editoras científicas. Cabe citar aqui a existência do Projeto de Lei n. 1120/ 2007, que tem como objetivo demubaras barreiras do acesso à informa ção científica. Ele prevê, por exemplo, que todas as instituições de nível superior disponibilizem a produção docente e disc ente de forma livre pela rede. Existe inclusive um aba ixo-assina do on-line em apoio a o projeto. Se ele fora prova do, o Brasil será pioneiro na adoção de uma política de livre acesso - e certamente o campo brasileiro dos estudos feministas e de gênero tem bastante a contribuir em relação a isso.

Um dos grandes desafios é o de sustentabilidade dos porta is de livre acesso, mas me parece que a sexperiências a tua is vêm a pontando a lguns ca minhos, como a procura porfontes a ltema tivas de fina nciamento, a tra vés de projetos específic os e de trabalhos em equipe e forma ção de coletivos de trabalho (como temos feito nosúltimosa nos em relação à edição impressa da REF).

2) 0 segundo ponto diz respeito à possibilidade de se utilizarem os espaços de public a ção on-line pa ra construir a rticulações e redes de troca de informa ções, bibliotecas digitais, um banco de dados com informações sobre as pesquisas em andamento no campo do gênero, um estímulo a outras publicações feministas. Sabemos que um dos grandes problemas dos periódicos acadêmic os é o de distribuição. Atra vés do portal, é possível que qualquerpessoa, em qualquerponto do Brasil, da América Latina e do mundo que tenha a cesso à internet leia a REF, por exemplo. Mas além do a cesso às publicações, pode-se pensar no reforço das redes a partir desse e de outros porta is - que podem ser artic ula dos uns com os outros. Em relação especificamente à América Latina, observa-se nos últimos anos um signific a tivo a umento de artigos propostos para a REF em língua espanhola vindos de países como Chile, Peru, Argentina e Cuba, o que demonstra que tanto a REF já é uma revista conhecida e respeita da entre as pesquisa doras desses países, quanto que há uma vontade porparte dessas pesquisadoras de se fazer conhecer pelo público brasileiro e de dialogar com o campo acadêmico brasileiro.

3) Uma terc eira questão, que não tivemos tempo de desenvolveraqui, mas que tem sido tratada em outros fóruns, diz respeito a uma política de tradução da produção acadêmica no campo feminista. A iniciativa de criação da SciELO Social Science, por exemplo, que busca darvisibilidade à produção brasileira ao traduzi-la para o inglês, é uma experiência fundamental de reversão do quadro atual de uma política de tra dução (parcial) de mão única: do inglês para as "línguas periféricas". Parcial porque no Brasil inexiste um projeto c la ro de versão para o português de textosfunda menta is no campo das Humanas, e mesmo um desestímulo a isso por parte das agências que financiam os 
periódic os acadêmic os e científic os. Isso cria uma dificuldade imensa, por exemplo, em relação aos cursos de graduação. A REF tem adotado uma política de tradução e public ação de textos não inéditos, mas que serão úteis para leitorase leitores que não têm acesso a suas versões origina is (não a penas em inglês) e não conhecem inglês ou outra língua estrangeira. No caso do inverso, ou seja, da tradução da produção brasileira para o ing lês ou para outras línguas, a situação é ma is precá ria a inda, com raras iniciativas (a SSS sendo uma delas) de implementação de uma nova perspectiva.

4) Por fim, uma última questão diz respeito à relação entre a edição impressa da revista e suas edições eletrônicas. Até este momento não se constata uma diminuição das vendas (diretas ou por assinatura) da REF a pós a construção do Portal e de sua disponibilização on-line. Pelo contrário, em nossas experiências de venda da Revista em encontros acadêmicos ou do movimento feminista pelo Brasil, em que sempre que é possível buscamos levar a Revista, instalar um balcão de vendas dos números avulsos e de assinaturas, o que se percebe é uma procura muito grande pela Revista por parte de estudantes, professoras, pesquisa doras, militantes de ONG s de vária s partes do Pa ís. Se por um lado percebe-se um estímulo à produção editorial eletrônica, à criação de novas revista son-line etc., por outro existe uma dific uldade muito grande porparte dasinstituiç ões de fomento e dos órgãos avaliadores em julgar da mesma maneira periódicos exclusivamente eletrônicos. Por enquanto, o que a gente pode constatar é que a versão eletrônica não tem concomido com a impressa, tem antesfortalecido a edição impressa da REF. Vamosvero que o futuro dirá.

[Rec ebido em janeiro de 2008 e aceito para publicação em março de 2008]

The Digital Editions of Revista Estudos Feministas (and the Democratization of the Access to the Scientific and Scademic Production)

Abstract: In this artic le we describe the electronic editions of Revista Estudos Feministas and our contribution towards a politics of democratization of the access to scientific and academic production. After a brief description of the three spaces of elec tronic ed itions of REF (the Electronic Library Scielo, the Scielo Social Sc ience Portal and the Feminist Portal), we discuss the contribution of gender and feminist studies for the democ ratization of the access to the sc ientific and academic production.

Key Words: Feminist and Gender Studies; Feminist Public ations; Electronic Public ations; Democratization of Sc ientific Production. 